\section{Cannabisanbau für Schmerzpatient erlaubt}

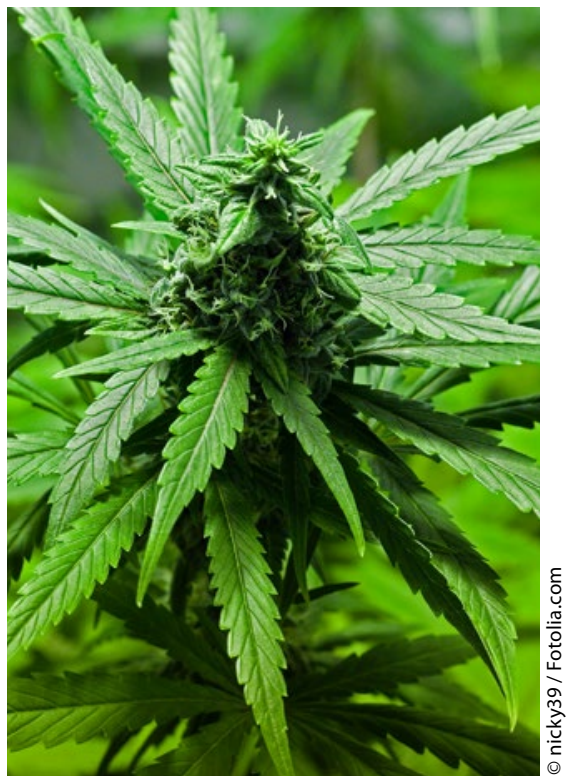

— Schwerkranken Patienten ist erstmals die Möglichkeit zum Eigenanbau von Cannabis zu medizinischen Zwecken eröffnet worden. In einem wegweisenden Urteil hat das Bundesverwaltungsgericht in Leipzig entschieden, dass das Bundesinstitut für Arzneimittel und Medizinprodukte (BfArM) einem an Multipler Sklerose (MS) erkrankten Mann eine Ausnahmegenehmigung zum Eigenanbau erteilen muss. Das ist in solch einem Fall bisher noch nie erfolgt.

Der 52 Jahre alte Mann leidet seit rund 30 Jahren an MS und konsumiert zur Linderung der Symptome regelmäßig Cannabis, zwischen drei und vier Gramm am Tag. Eine Therapiealternative gibt es aus der Sicht seiner Ärzte nicht. Dronabinol zeigt bei ihm bei Weitem nicht die qualitativ vergleichbare schmerzlindernde Wirkung wie Cannabis.
Mittlerweile besitzt der Mann eine Erlaubnis, Medizinalhanf in der Apotheke zu erwerben. Doch dort kostet ein Gramm etwa $15 €$. Bei seinem Konsum lägen die Kosten pro Monat somit bei mindestens $1.500 €$. Die Krankenkasse übernimmt diese Summe nicht. Seit Jahren baut der MS-Patient daher selbst Cannabis in seinem Badezimmer an. Juristisch belangt wird er dafür wegen eines "gerechtfertigten Notstandes" nicht, wie ein Gericht schon 2005 geurteilt hat. Eine offizielle Genehmigung verweigerte ihm das BfArM jedoch mit Verweis unter anderem auf die Arzneimittelsicherheit. Vor Gericht konnte außerdem geltend gemacht werden, dass das Bundesgesundheitsministerium ja derzeit an einer Gesetzesänderung arbeitet, die darauf abzielt, die Krankenkassen zur Kostenerstattung für Medizinalhanf zu verpflichten. Wirksam wird diese Gesetzesänderung aber frühestens im Jahr 2019. Zumindest bis dahin darf der Kläger wohl selbst sein Cannabis zur Schmerzlinderung anbauen.

\section{Celecoxib \\ Schmerzmittel mit Antitumorwirkung}

— Forscher entdeckten einen neuen Antikrebsmechanismus des Schmerzmittels Celecoxib. Das Team um Professor Burkhard Hinz vom Institut für Toxikologie und Pharmakologie der Universitätsmedizin Rostock konnte nachweisen, dass die Gabe von Celeboxib zur erhöhten Bildung eines spezifischen Oberflächenproteins auf Lungentumorzellen führt. Die Expression des Proteins verstärkt die Bindung von spezialisierten Immunzellen, sogenannten Killerzellen, an die Tumorzellen, sodass diese eliminiert werden. Nachgewiesen wurde die Wirkung bisher nur in Zellkulturversuchen, heißt es in einer Meldung der Universität Rostock. Außerdem beschränkte sich der Effekt auf das in Deutschland zur Therapie von Schmerzen und Entzündungen bei Gelenkerkrankungen eingesetzte Celecoxib. Für strukturähnliche Schmerzmittel konnte der tumorzellenzerstörende Mechanismus nicht gezeigt werden. Allerdings benötige man zum Erreichen der Antikrebswirkung vergleichsweise hohe Konzentrationen des Schmerzmittels, erklärte Hinz.

\title{
Neuropeptid
}

\section{Oxytocin stillt Schmerz auf doppelte Weise}

— Forscher haben im Gehirn ein "Schmerzkontrollzentrum" identifiziert. Dort kooperieren zwei verschiedene Typen Oxytocin produzierender Nervenzellen und unterdrücken so den Schmerz gleich doppelt: Oxytocin blockiert die Weiterleitung von Schmerzreizen im Rückenmark und hemmt gleichzeitig die Schmerzempfindung in der Körperperipherie, heißt es in einer gemeinsamen Mitteilung des Deutschen Krebsforschungszentrums, des Zentralinstituts für Seelische Gesundheit Mannheim und des Exzellenzclusters CellNetworks.

Die Wissenschaftler entdeckten an Ratten einen Bereich im Hypothalamus, der als Schmerzkontrollzentrum funktioniert [Eliava M et al. Neuron 2016; 89: 1291 - 304]. Nur etwa 30 parvozelluläre Oxytocin produzierenden Nervenzellen orchestrieren dort die schmerzhemmende Wirkung des Neuropeptids.

Die kleine Gruppe der neu entdeckten Neuronen tritt bei akuten Schmerzen oder Entzündungen in Aktion: Unter diesen Bedingungen aktivieren sie die magnozellulären Oxytocin produzierenden Neuronen im benachbarten supraoptischen Nukleus des Hypothalamus. Das löst die Oxytocinausschüttung in die Blutbahnen aus und lindert dadurch diffus die Schmerzempfindung, die über periphere Nervenzellen vermittelt wird, heißt es in der Mitteilung.

Auf der anderen Seite reichen die Neuronen des Schmerzkontrollzentrums mit langen Ausläufern bis in tiefe Schichten des Rückenmarks. Dort speisen sie das Neuropeptid exakt an der Stelle des zentralen Nervensystems ein, wo die Intensität der Schmerzwahrnehmung weitergeleitet wird. Die neu entdeckten Neuronen hemmen den Schmerz also auf doppelte Weise: Ein schneller schmerzstillender Effekt entsteht durch Filtern des Schmerzreizes im zentralen Nervensystem. Etwas länger dauert es, bis das ins Blut ausgeschüttete Oxytocin die Schmerzempfindung lindert. 